\title{
Editorials
}

\section{Helping patients with common mental health problems return to work}

\section{INTRODUCTION}

Sickness absence tells us much about health and wellbeing at work. The two largest causes of sickness absence are, unsurprisingly, musculoskeletal disorders and common mental health problems (CMHP), that is, anxiety, depression, and stress. Much research has postulated how work and CMHP may be related. High levels of overall work attendance, despite the prevalence of CMHP in the population, suggests that trying to determine cause and effect may be futile - there being many variables. However, given the importance and prevalence of CMHP, we will consider recent research to help determine the main actions GPs can take to assist their patients.

\section{BACKGROUND}

In any year perhaps 1 in 4 people has a diagnosable mental health condition and 9 out of 10 adults with a CMHP are supported in primary care, with annual estimated related economic and social costs of $€ 105$ billion: about two-thirds of the NHS budget. ${ }^{1}$ The cost to employers alone was estimated to be almost €35 billion last year. ${ }^{2}$ Global data indicate that CMHP will account for more than half of the economic burden from all non-communicable diseases over the next 20 years and 35\% of lost output. ${ }^{3}$ In 2016 CMHP accounted for 15.8 million lost working days: $11.5 \%$ of all UK sickness absence. ${ }^{4}$ In England, of almost 6 million fit notes that included a known diagnosis, morewere issued for mental and behavioural disorders (31.3\%) than for any other disorder, with certification for anxiety and stress up by $14 \%$ in the last year. ${ }^{5}$ Certification for CMHP is also more likely to exceed 12 weeks compared with all causes of sickness absence (21.5\% compared with $14.7 \%$ ). ${ }^{5}$ The cost of presenteeism (being at work while unwell) is estimated to be about twice that of absenteeism, ${ }^{2}$ but this is difficult to confirm. Many factors are at play in working life, such as diverse personalities and perceptions, financial needs, relationships, motivations, and frustrations.

\section{STIGMA AT WORK}

Only $13 \%$ of employers provide access to an occupational health service (OHS). In part this may be attributable to the belief that work is safer, as many 'heavy industry' and physically demanding manufacturing jobs have been replaced by service sector jobs or 'light industry'. However, employers should

"With little access to OHS it is unsurprising that only $28 \%$ of employees feel able to involve anyone at work, fearing a negative impact.

appreciate that CMHP, work related or not, are pervasive and represent a significant source of avoidable people costs, business risks, and lost productivity. With little access to $\mathrm{OHS}$ it is unsurprising that only $28 \%$ of employees feel able to involve anyone at work, fearing a negative impact. ${ }^{6}$ Only 13\% feel able to disclose a mental health issue to their manager and, of those who did, $15 \%$ were subject to disciplinary procedures, demotion, or dismissal - unsurprisingly, they are more likely to turn to GPs, family, and friends. ${ }^{6}$ Black, Asian, and minority ethnic employees are even less likely to feel comfortable talking about CMHP at work or to consult a GP compared with white employees (20\% compared with 29\%). 6

\section{DOCTORS WHO HAVE A COMMON MENTAL HEALTH PROBLEM}

It is often reported that doctors have a higher incidence of CMHP than other professionals. An anonymous survey of 1954 UK doctors indicated that $60 \%$ had experienced CMHP; trainees, staff, and associate specialty doctors and locums were most vulnerable. Doctors were reluctant to disclose CMHP because of concerns about stigma, confidentiality, and not understanding available support structures.? A multilevel regression study reported that the incidence of work-related mental illness between 2001-2014 increased for doctors, whereas it decreased or was static for other occupations, the difference being statistically significant. ${ }^{8}$ A survey of 3695 UK medical graduates reported that $44 \%$ felt that working as a doctor had adverse effects on their health or wellbeing (GPs 47\%; hospital doctors 42\%). Of the $79.1 \%$ who answered 'yes', they cited 'stress/work-life balance/workload'. 9 GPs as patients have reported issues related to stigma, confidentiality, privacy, and difficulties accessing good-quality treatment. ${ }^{10}$

\section{RETURN TO WORK INTERVENTIONS}

Generally, for people who are off sick, early assessment, early rehabilitation, and work/ workplace adjustments have been shown to be effective in helping return to work (RTW). ${ }^{1}$
Adjustments might include, for example, phased RTW, reduced hours, reallocating some work, or providing additional support to manage workload. There are few high-quality studies of RTW interventions for CMHP, which may explain the lack of consensus between reviews. ${ }^{11}$ However, evidence relating to depression shows moderatequality evidence that adding either a workdirected intervention or cognitive behavioural therapy (CBT) to occupational or primary care have the potential to reduce sickness absence. However, the number of studies evaluating these types of interventions is limited. ${ }^{12}$

\section{RETURN TO WORK BARRIERS AND FACILITATORS}

A systematic review reported strong evidence that the following were barriers to RTW depression, comorbidity, previous sickness absence, and older age; and moderate evidence for anxiety, job strain, psychological job demands, and exposure to violence or bullying. There was moderate evidence that supervisor/co-worker support, work ability, positive RTW expectations, and higher socioeconomic status were facilitators. ${ }^{13}$

A small qualitative study reported additional barriers, that is, patients disliking their work, fear of further illness, caring responsibilities at home, employer's sick pay incentivising absence, and inability to contact an occupational physician. ${ }^{14}$ A small group of GPs regarded facilitators as including the demonstration of care and empathy, motivational interviewing techniques, having a RTW caseworker/coach, and collaboration with an occupational physician. ${ }^{14}$

\section{THE ROLE OF PRIMARY CARE}

In that study, GPs saw their responsibilities to include early diagnosis; identifying the cause; empowering patients to find their own solutions; psycho-education; regular review; advising regular contact with work; and collaborating with an occupational physician. ${ }^{14}$ Another small study highlighted the significant role of GPs in preventing longterm work disability in depression. ${ }^{15}$ When 
steering patients towards psychotherapy services, GPs preferred an Employee Assistance Programme (EAP) because of its focus on work issues, and private resources for patients with insurance. Many large employers provide employees and their dependants with access to a confidential EAP for personal advisory and psychological support and/or counselling.

\section{WORK VERSUS WORKLESSNESS}

Although a patient should not return to work that has caused their problem without a workplace risk assessment (RA) or RA review, it is important to consider adverse consequences of sickness absence. Work can be therapeutic through activity, distraction, social engagement, motivation, structure, and self-esteem. NICE signposts patients and clinicians to a decision aid which advises that RTW is good for physical and mental health, helps prevent relapses, and jobs that match the patient's skills and provide employer support are good for mental health. ${ }^{16}$

\section{RECOMMENDATIONS}

GPs who see a working patient who presents to them with a CMHP should consider the following:

- ask about occupational causes or aggravators;

- ask whether the manager and co-workers are supportive;

- ask if they have access to an EAP/private health care (for counselling); and

- ask about access to OHS and direct them to this. If not:

- remind patients with disability about Access to Work ${ }^{17}$ services' support;

- advise that work is generally good for physical and mental health, and being out of work is associated with poorer physical and mental health;

- consider whether a fit note is needed to certify absence and/or to indicate possible adaptations/altered hours or a phased RTW, which may help with health and to identify solutions; and

- if they are off sick, explore their beliefs about health and work and return to work expectations, and advise them to stay in regular contact with work.

\section{CONCLUSIONS}

CMHP often affect work, and vice versa. The data referred to suggest that most working people with CMHP do not attend their GP or seek GP fit note certification. It is always worth considering the wider picture if a patient does attend the surgery with a CMHP. Workload or relationships are often blamed, but things may be more complex and personal accountabilities may not be volunteered to the GP. Patients may use sickness certification as an avoidance tactic so GPs should seek to understand the cause of presentation as part of assessment and management. ${ }^{14}$ Ongoing sickness absence and potential worklessness and related difficulties are likely to be harmful and costly to all concerned.

GPs can help to offer or signpost support and solutions in timely and effective ways. It is always worth remembering to ask about access to an OHS, because they can help address patient/GP concerns and to an EAP or private health care (for counselling or CBT), which may be available to employees and their families. Communication with the

\section{ADDRESS FOR CORRESPONDENCE}

\section{Paul J Nicholson}

16 North Block, County Hall Apartments, London SE1 7PJ, UK

\section{Email: pjnicholson民adoctors.org.uk}

employer is encouraged, for example, if something impacting on health requires to be addressed in the workplace, which can be done using the fit note.

\section{Paul J Nicholson,}

Occupational Physician, London.

\section{John CD Gration,}

GP and Occupational Physician, Rochester, Kent.

\section{Provenance}

Freely submitted; externally peer reviewed.

DOI: https://doi.org/10.3399/bjgp18X695333

\section{REFERENCES}

1. Chambers R, Schmid M, Birch-Jones J. The five year forward view for mental health. A report from the independent Mental Health Taskforce to the NHS in England. London, 2016.

2. Parsonage M, Saini D. Mental health at work the business costs ten years on. London: Centre for Mental Health, 2017. https://unw. centreformentalhealth.org.uk/mental-healthat-work-report laccessed 26 Feb 2017).

3. Bloom DE, Cafiero ET, Jané-Llopis E, et al. The global economic burden of non-communicable diseases. Geneva: World Economic Forum, 2011

4. Office for National Statistics. Sickness absence in the labour market: 2016. Analysis describing sickness absence rates of workers in the UK labour market. Newport: ONS, 2017.

5. NHS Digital. Fit notes issued by GP practices, England. December 2014-March 2017. 2017. http://wnw.digital.nhs.uk/catalogue/PUB30068 laccessed 26 Feb 2017).

6. Business in the Community. Mental health at work report 2017. https://wellbeing.bitc.org.uk/ all-resources/research-articles/mental-healthwork-report-2017 (accessed 26 Feb 2017).

7. Cohen D, Winstanley SJ, Greene G. Understanding doctors' attitudes towards self-disclosure of mental ill health. Occup Med (Lond) 2016; 66(5): 383-389.

8. Zhou AY, Carder M, Gittins M, et al. Workrelated ill health in doctors working in Great Britain: incidence rates and trends. $\mathrm{Br} J$ Psychiatry 2017; 211(5): 310-315

9. Smith F, Goldacre MJ, Lambert TW. Adverse effects on health and wellbeing of working as a doctor: views of the UK medical graduates of 1974 and 1977 surveyed in 2014. JR Soc Med 2017: 110(5): 198-207.

10. Spiers J, Buszewicz M, Chew-Graham CA, et al. Barriers, facilitators, and survival strategies for GPs seeking treatment for distress: a qualitative study. Br J Gen Pract 2017: DOl: https://doi. org/10.3399/bjgp17X692573.

11. Nicholson PJ. Occupational health: the value proposition. Society of Occupational Medicine, 2017. https://www.som.org.uk/sites/som.org. uk/files/Occupational\%20health\%20-\%20 the\%20value\%20proposition_0.pdf laccessed 23 Feb 2018).

12. Nieuwenhuijsen $\mathrm{K}$, Faber $B$, Verbeek JH, et al. Interventions to improve return to work in depressed people. Cochrane Database Syst Rev 2014; (12): CD006237.

13. Gragnano A, Negrini A, Miglioretti M, Corbière M. Common psychosocial factors predicting return to work after common mental disorders, cardiovascular diseases, and cancers: a review of reviews supporting a cross-disease approach. J Occup Rehabil 2017; 6 Jun. DOI: 10.1007/s10926-017-9714-1. [Epub ahead of print].

14. Joosen M, Arends I, Lugtenberg M, et al. Barriers to and facilitators of return to work after sick leave in workers with common mental disorders: Perspectives of workers, mental health professionals, occupational health professionals, general physicians and managers. Wigston: Institution of Occupational Safety and Health, 2017.

15. Sylvain C, Durand MJ, Maillette P, Lamothe L. How do general practitioners contribute to preventing long-term work disability of their patients suffering from depressive disorders? A qualitative study. BMC Fam Pract 2016; 17: 71.

16. Kongs-Taylor H, Lockett H, Clapham Howard F, et al. Option Grid ${ }^{\text {IM }}$ decision aid: mental health conditions: return to work or not? Dartmouth Institute for Health Policy \& Clinical Practice, 2015. http://optiongrid.org/option-grids/gridlanding/6 (accessed 6 Mar 2018).

17. GOV.UK. Get help at work if you're disabled or have a health condition (Access to Work). https://wnw.gov.uk/access-to-work/overview (accessed 23 Feb 2018). 